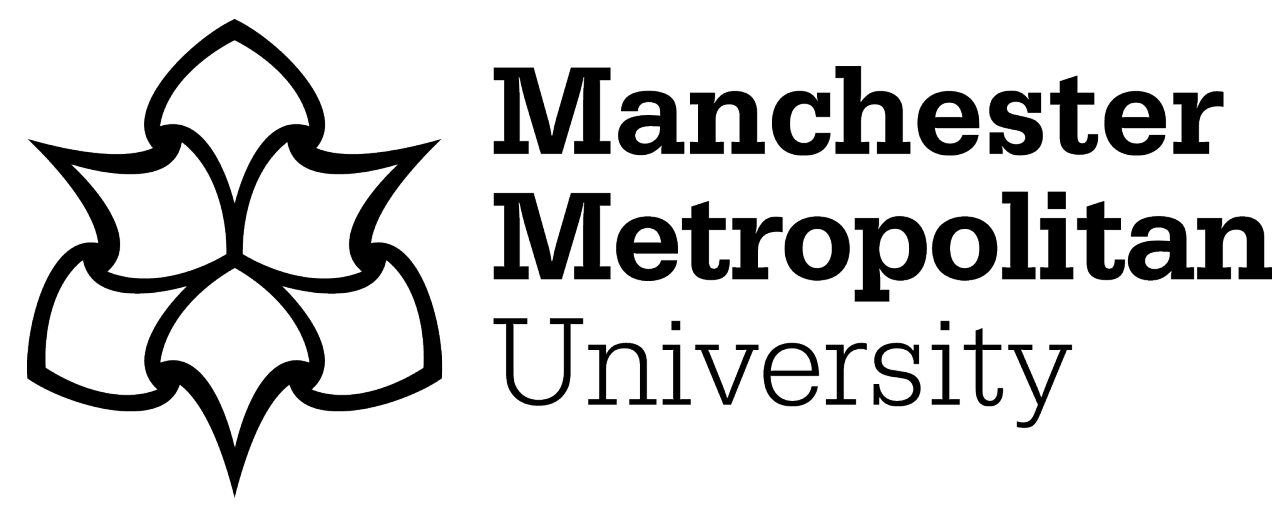

Antoniadou, Marilena and Quinlan, Kathleen (2020) Thriving on challenges: how immigrant academics regulate emotional experiences during acculturation. Studies in Higher Education, 45 (1). pp. 71-85. ISSN 0307-5079

Downloaded from: https://e-space.mmu.ac.uk/621454/

Version: Accepted Version

Publisher: Taylor \& Francis (Routledge)

DOI: https://doi.org/10.1080/03075079.2018.1512567

Please cite the published version 


\title{
Thriving on challenges: how immigrant academics regulate emotional experiences during acculturation
}

\author{
Marilena Antoniadou ${ }^{\mathrm{a}}$ and Kathleen M. Quinlan ${ }^{\mathrm{b}}{ }^{\mathrm{b}}$

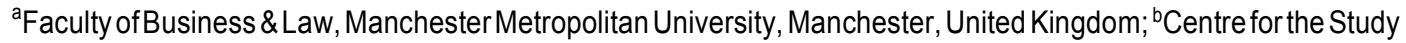 \\ of Higher Education, University of Kent, Kent, United Kingdom
}

\begin{abstract}
Transnational academic mobility is of growing importance in higher education. Yet, the acculturation for individual academics is challenging. Taking a phenomenological approach, we interviewed twenty foreignborn academics, who had been living and working in the UK for at least one year, and analysed their emotional experiences of acculturation by chronological stages. Then, using Gross's (Gross, J. J. 1998. "Antecedentand Response-Focused Emotion Regulation: Divergent Consequences for Experience, Expression, and Physiology." Journal of Personality and Social Psychology 74 (1): 224-237; Gross, J. J. 2014. "Emotion Regulation: Conceptual and Empirical Foundations." In Handbook of Emotion Regulation, 2nd ed., edited by J. J. Gross, 3-20. New York: Guilford) model of emotion regulation, we analysed how participants used emotion regulation processes throughout their adaptation to their new environments. The study makes an original contribution firstly by applying a model of emotion regulation not previously used in researching academic life. Secondly, this study shows that, unlike stage theories, acculturation is not experienced primarily in linear stages, but as an ongoing process during which immigrant academics actively work on changing the things that challenge them. Thirdly, the findings emphasise the contributions rather than deficits of immigrant academics. Implications for supporting immigrant academics' acculturation are discussed.
\end{abstract}

KEYWORDS

Emotion regulation; internationalisation; crosscultural transition; faculty; adaptation

\section{Introduction}

In the knowledge economy era, transnational academic mobility in higher education (HE) has become an indicator of economic competitiveness (Jiang etal. 2010; Kimand Locke 2010). National and supra-national policy frameworks, such as the European Higher Education Area's Bologna process and Lisbon Declaration (European Commission/EACEA/Eurydice 2015), and the European Research Council's Green Paper (CEC 2007) have facilitated and reinforced highly-skilled migration. In the UK HE sector, for example, over a quarter (28\%) of academic staff during the years 2015/16 were non-UK nationals (HESA 2017), compared with 14\% over the period 2005-2008 (UCEA 2008). Sixteen percent (16\%) are EU nationals (excluding UK), and twelve percent (12\%) come from outside of the EU (HESA 2017). With the UK professoriate ageing, international recruitment continues to be strategically important (Universities UK 2015).

Foreign-born academics have the potential to strengthen research and knowledge production, modernise pedagogy and assessment, and promote an awareness of interculturalism (Sanderson

CONTACT Marilena Antoniadou m.antoniadou@mmu.ac.uk EFaculty of Business \& Law, Manchester Metropolitan University, All Saints Campus, Oxford Road, Manchester M15 6BH, United Kingdom 
2011). Students perceive that their tutors' foreignness and intercultural sensitivity helped them to overcome stereotypes and exposed them to diff erent perspectives, places and people (Alberts 2008; Pherali 2012). However, the emotional experiences of immigrant academics working in the UK related to their integration in their new environments are relatively unexplored (e.g. Jiang et al. 2010; Kim and Locke 2010; Sanderson 2011).

An original contribution of this article is that it identifies processes of psychological, sociocultural and professional adaptation of immigrant academics in the UK with particular emphasis on the factors thathelp or hinder this adaptation. First, we review the debates around cultural and academic adaptation and then present the conceptual frameworks that guided data collection and analysis.

\section{Immigrant academics' acculturation}

Being an immigrant academic involves a process of adaptation, described as academic acculturation, during which 'one becomes a part of a group (e.g. institution, department) and integrates with its members, while possibly influencing the host group with one's own life experience and academic expertise' (Jiang et al. 2010,157). Similarly, adaptation refers to changes and outcomes that occur in response to individuals experiencing acculturation (Berry 1997).

The psychological consequences of relocation for immigrant academics are highly variable, depending on social factors in the host culture and phenomena that exist both prior to and during the course of acculturation. Some of the challenges include language barriers, students being accustomed to diff erent teaching methods, financial hardship, uncertainty about residency, and handling cultural differences (Alberts 2008; Collins 2008; Green and Myatt 2011; Luxon and Peelo 2009; Moody 2004; Pherali 2012; Tange 2010). Dealing with such difficulties may bring a sense of inadequacy, disorientation (Foote et al. 2008; Lund, Hibbins, and Barker 2007; Trowler 1998), and isolation due to difficulties in creating and sustaining meaningful friendships (Richardson and Zikic 2007). Universities are not always attuned to the needs of immigrant academics and their families, leaving them to simply sink or swim in the new job (Mizzi 2013).

\section{Theoretical frameworks}

Seminal social psychological research represents individuals' cross-cultural adaptation in stages of adjustment. Oberg's (1960) notion of 'culture shock' theorises the personal experience of cultural transition as a set of emotional reactions to the loss of perceptual reinforcements from one's own culture while new stimuli have little or no meaning. These reactions, occurring in sequential stages, are (a)honeymoon, characterised by fascination, elation and optimism, (b) crisis, a stage of hostility and emotionally stereotyped attitudes towards the host nation and increased association with fellow sojourners, (c) recovery, characterised by increased ability to get around in the new environment, and (d) adjustment as the last stage, when new customs are accepted and enjoyed. Similar adaptation models linked to discrete psychological stages are Adler's (1975) model of contact-disintegration-reintegration-autonomy-independence, the U-curve concept by Lysgaard (1955)whereby migrants experience a peak honeymoon period, a period of disillusionment followed by a gradual adaptation into a new culture, and Hopson and Adams (1976) model whereby individuals might experience patterns of feelings, such as shock, denial, depression, acceptance, testing, searching for meanings, and internalisation.

These stage-state frameworks, however, have been widely critiqued (e.g. Church 1982; Green and Myatt 2011; Lund, Hibbins, and Barker 2007) as making general assumptions that only reflect the most common patterns of adjustment of most travellers. Furthermore, they neither capture the complexity and unpredictability of the process nor cases when the stages occur out of sequence, are repeated, regulated, or even absent. For example, Zhou et al. $(2008,73)$ critiqued early models of cultural transition, noting that they were based on mental health issues, whereas later models focused on wider social, psychological and educational theories that regarded the traveller 'as an active agent 
rather than the victim of pathology'. Newer social psychological theories have viewed geographical movement not as a static state, in which individuals remain and suffer, but a process in which they are active agents and experience multiple changes in self-esteem (Luxon and Peelo 2009).

Similarly, studies of immigrant academics' experiences have emphasised the negatively-perceived aspects, mainly anxiety, transience and risk (e.g. Hsieh 2012; Richardson and Zikic 2007), with limited studies (e.g. Foote et al. 2008; Zhou et al. 2008) reporting the determination, flexibility and coping strategies that characterise academics' international adaptation. Studies (e.g. Barkhuizen 2002; Green and Myatt 2011) that have described immigrant academics' transition as an iterative process of overlapping phases, during which they actively attempt to adapt, were not only based on a very small number of participants ( $n=1, n=8$ respectively), but also did not distinguish between early-career and immigrant academic adaptation.

\section{Emotion regulation processes}

This study makes a unique contribution by drawing on a model of adult emotional regulation (Gross 1998,2014 ) to illustrate how international acculturation is not a fixed state characterised by a sequence of emotional reactions, but is instead an ongoing process in which immigrant academics use their experience and personal resources thrive in their new environments. Emotion regulation is an important determinant of psychological and emotional adaptation (Gross 2014). Thus, examining how immigrant academics experience, express or regulate their emotions enriches our understanding of their adjustment to their new social and professional environments.

Emotion regulation refers to individuals' attempts to influence which emotions to have, when to have them, and how these are experienced or expressed (Gross 1998). According to Gross's highly cited process model $(1998,2014)$, adults regulate their emotions at five points along a timeline of emotion generation. Four of these points are prior to the emotional response itself (antecedentfocused mechanisms), while the last (suppression) occurs as a way of modulating the expression of emotional responses already being felt (response-focused mechanisms). The first four points include (a) selecting the situation (avoiding negative situations or deliberately choosing happier situations); (b) modifying the situation once one is in it; (c) focusing attention on particular aspects; and (d) reappraisal, in which one takes a different perspective on a situation, attaching different meanings to it, with diff erent emotional consequences. Once the emotion is triggered, it may be expressed or sup- pression may be used to hide its behavioural manifestation. Thus, adults consciously (and uncon- sciously) think and act to manipulate situations, the focus of their attention, and the meaning they attach to events, as well as modulating their emotional response once it happens.

Recent versions of this model have introduced feedback pathways of emotion regulation and suggested the eff ectiveness of using multiple emotion regulation strategies in parallel (Gross and Thompson 2007). An extension of Gross's process model (2015) introduced the notion of valuation systems to address how emotion regulation strategies can be separated into three decision-point stages, namely identification (whether to regulate), selection (which strategy to use to regulate emotion), and implementation (implementing a particular tactic suited to a situation). Personality traits and emotional abilities, motives, and context-specific factors, such as emotional intensity and other contextual variables can influence these stages of emotion regulation and their effectiveness (Gross 2015; Tamir 2016). Research on consequences of using different types ('families') of emotion regulation has focused almost exclusively on contrasting reappraisal and suppression and has demonstrated that, generally, reappraisal has greater efficacy as compared to suppression (e.g. Gross and John 2003; John and Gross 2004; Gross 2014).

The control-value theory of achievement emotions (Pekrun 2006; Pekrun and Perry 2014) offers another emotional regulation process relevant to this study. Pekrun (2006; Pekrun and Perry 2014) postulates that emotions can be regulated by targeting the emotion itself or related attentional pro- cesses and appraisals. Regulation can, thus, be (a) emotion-oriented, by focusing attention on the emotion, such as using relaxation techniques or distracting it away with 
suppression; (b) appraisal-oriented, by changing how the situation, task or environment is perceived; (c) competence-oriented, which involves targeting the achievement outcome by taking actions to improve competence; and (d) situation-oriented, by selecting tasks and environments to match individual goals and compe- tencies. The control-value theory accords with Gross's $(1998,2014)$ emotion regulation theory insofar as individuals can regulate an emotion by using situation selection and modification, attentional deployment, reappraisal or suppression. However, Pekrun (2006) also postulates that people can try to regulate their emotions by changing the internal situation through competency enhancement. Although Gross's (1998,2014)families of emotion regulation have been incorporated in work set- tings (e.g. Diefendorff, Richard, and Yang 2008), there is no research on the emotion regulation pro- cesses that immigrant academics use during their acculturation. This study aimed to: (i) increase understanding of the emotional experiences of immigrant academics during their sociocultural and educational acculturation in UKHE, and (ii) identify patterns of emotion regulation mechanisms

they use and the general psychological mechanisms enacted in this particular context.

\section{Methods}

To gain rich, contextualised understandings of immigrant academics' emotional experiences of living and working in the UK, a phenomenological approach was used (Sandberg 2000). While other qualitative methodologies exist that use similar analytical processes (narrative inquiry, ethnography, grounded theory), this study focused on interpretive phenomenology to best capture the meanings of those experiences from the participants' perspective. For example, narrative inquiry also considers the narratives of individuals from a social constructionist perspective. However, phenomenology focuses on the content of the subjective experience as derived from stories and not how the stories are told (Gill 2014). Phenomenology does notaim to explain meanings in relation to particular cultures as ethnography does, nor does it focus only on situations with an interactional or symbolic element to them, as grounded theory does (Goulding 2005). Specifically, Benner's (1994) interpretive phenomenology is beneficial in terms of theory building based around lived experiences of a phenomenon - in this study, the phenomenon of academic acculturation.

\section{Participants}

An immigrant academic was defined as a foreign-born individual on a full-time teaching and/or research contract at a UK university who had been living and working in the UK for more than one year and was not on sabbatical from or exchange from a foreign university (Richardson and McKenna 2003). This definition was set out in the invitation to participate in the study.

Interviews were conducted between January and May 2016, before the UK's European Union membership referendum in June 2016. There were twenty participants (ten females, ten males), aged 33-57 years, from 13 cultural backgrounds and diverse academic disciplines, who had worked in UK HE from 1.5 to 16 years. All were based in one of three universities in north-western England, the third most popular UK geographic region for immigrant academics, after London and the south-east England (HESA 2017). At an institutional level, non-UK academics accounted for $28 \%, 16.5 \%$ and $16 \%$ of all academic staff in these universities. The participants had varying levels of work experience in other contexts prior to the UK, with an average of 8 years in HE prior to the UK (Table 1).

\section{The interpretive procedure}

Following the institutionally approved ethics protocol, participants were briefed about the purpose of the study, and their rights to anonymity and withdrawal at any time. Semi-structured interviews were conducted at each participant's workplace and enabled participants to discuss issues that were meaningful to them. In line with previous research on academic acculturation (Jiang et al. 2010), 
Table 1. Participants' profile.

\begin{tabular}{lclcllr}
\hline Participant & Gender & Age & Years in UK HE & Nationality & Position & Years in HE (prior to UK) \\
\hline Rudolf & $\mathrm{M}$ & $50 \mathrm{~s}$ & 15 & Austria & Professor & 13 \\
Sven & $\mathrm{M}$ & $60 \mathrm{~s}$ & 9 & Sweden & Professor & 15 \\
Konstantina & $\mathrm{F}$ & $30 \mathrm{~s}$ & 5 & Greece & Lecturer & 3 \\
Aphrodite & $\mathrm{F}$ & $40 \mathrm{~s}$ & 16 & Greece & Senior Lecturer & 5 \\
Anastasia & $\mathrm{F}$ & $30 \mathrm{~s}$ & 10 & Cyprus & Senior Lecturer & 4 \\
Fabio & $\mathrm{M}$ & $30 \mathrm{~s}$ & 3 & Italy & Lecturer & 4 \\
Andrea & $\mathrm{M}$ & $30 \mathrm{~s}$ & 3.5 & Italy & Senior Lecturer & 7 \\
Audra & $\mathrm{F}$ & $40 \mathrm{~s}$ & 1.5 & America & Senior Lecturer & 15 \\
Qi & $\mathrm{M}$ & $40 \mathrm{~s}$ & 8 & China & Researcher & 5 \\
Yu-Wang & $\mathrm{M}$ & $30 \mathrm{~s}$ & 7 & China & Researcher & 5 \\
Zhi & $\mathrm{F}$ & $40 \mathrm{~s}$ & 8 & China & Senior Lecturer & 5 \\
Olga & $\mathrm{F}$ & $50 \mathrm{~s}$ & 13 & Russia & Reader & 16 \\
David & $\mathrm{M}$ & $30 \mathrm{~s}$ & 5 & Germany & Senior Lecturer & 6 \\
Mollie & $\mathrm{F}$ & $40 \mathrm{~s}$ & 6 & America & Senior Lecturer & 7 \\
Roberto & $\mathrm{M}$ & $40 \mathrm{~s}$ & 4 & Puerto Rico & Senior Lecturer & 10 \\
Sungjun & $\mathrm{M}$ & $40 \mathrm{~s}$ & 6 & Hong Kong & Senior Lecturer & 8 \\
Marie & $\mathrm{F}$ & $40 \mathrm{~s}$ & 5 & France & Senior Lecturer & 9 \\
Oksana & $\mathrm{F}$ & $40 \mathrm{~s}$ & 8 & Russia & Senior Lecturer & 9 \\
Christos & $\mathrm{M}$ & $30 \mathrm{~s}$ & 4 & Greece & Lecturer & 3 \\
Mercedes & $\mathrm{F}$ & $40 \mathrm{~s}$ & 4 & Spain & Senior Lecturer & 11 \\
Average & & & 7 & & & 8
\end{tabular}

questions about participants' emotions followed four broad chronological periods: before coming to the UK, the early period of arrival, more recent and current experience, and the future. Examples of questions used in the interviews included: 'Describe an emotional situation you experienced as an immigrant academic during your first days', 'How did you respond to this situation?' Interviews lasted from one to two and a half hours and were all audio-recorded and transcribed verbatim.

When new informants did not reveal new findings and interpretations were clear, sampling stopped (Benner 1994). Data were analysed using guidelines for phenomenological interview analysis by Crist and Tanner (2003). The analysis was carried out in an ongoing iterative process in which we alternated between what the immigrant academics perceived of their acculturation and how they regulated their emotions during their acculturation. Phase 1 involved acquiring a general grasp of the first interviews by reading each transcript several times, with unclear pieces being tagged as lines of inquiry for further interviews. Some lines of inquiry involved the level of institutional support and provision of training during induction, as contrasting experiences were found amongst participants. Phase 2 involved identification of important themes, such as obstacles affecting the participants, with salient excerpts (exemplars) for each early participant's story. As researcher interpretations began to emerge, summaries of meaningful common patterns and con- cerns amongst informants were created. For example, it soon became evident that seeking inter- actions with fellow expatriates was common in many stories. Once this exemplar was identified, seeking beneficial interactions, on a broader level, began to be recognised in subsequent stories. We then continued to move back and forth between the transcripts and portions of the interpretation and carefully developed a range of exemplars to allow the reader to recognise the distinctions we made and to illustrate the patterns of emotion regulation strategies. In Phase 3, the written interpre- tive summary showed connections between meanings found within and across stories and constitu- tive patterns. The shared participant meanings, captured in the written interpretive summaries, were then compared with various theories of migrant transition, as outlined in the introduction, and with various theories of emotion, as outlined by Quinlan (2016). Emotional self-regulation best described what our participants experienced. Once a pattern of meaningful themes was identified, extracts from the interviews were used to demonstrate similarity or contrast. In Phase 4, final interviews addressed pending lines of inquiry, and in-depth interpretations of exemplars and interpretive sum- maries were developed. Phase 5 continued the final interpretation with the involvement of the 
second author who validated interpretations and themes and determined whether concerns had been answered and whether interpretation broadened possibilities for $\mathrm{HE}$ interventions and research.

\section{Findings}

Consistentwith phenomenological inquiry, we firstreportthe emotional experiences thatemerged in participants' own words during the four chronological periods (Jiang etal. 2010) that shaped the data collection. Then, we reinterpret the findings using Gross's $(1998,2014,2015)$ model of emotional regulation, expanded to include competence-oriented regulation (Pekrun and Perry 2014). The theoretical constructs appear in italics.

\section{Before coming to the UK}

Before coming to work in the UK, participants felt longstanding disappointment and frustration with their previous 'home' institutions and the lack of progression opportunities for them. This disappointment prompted them to seek academic positions in the UK. When they secured an academic post in the UK, they felt euphoria and excitement. A few mentioned feeling proud, seeing the off er as recognition of their strong curriculum vitae. Two participants, Rudolf and Sven, were headhunted based on their successful research activity, which they found gratifying. Olga chased a job in the UK, explaining:

The UK is the dream ... the feeling I had was one of a euphoric apprehension. I was excited that I managed to come here, and nervous of what would follow.

For Zhi, the UK also gave her the opportunity to fulfil her dream to further her career, something not possible in China:

It was frustrating how difficult it was to be promoted ... I was longing to being with the elite. I remember feeling excited about living an adventure. I couldn't wait to make the UK my home.

None of the participants referred to salary as a factor in moving to the UK. Instead, improved research opportunities, working in prestigious universities with highly cited academics, and enhancing their global academic profile were the main factors that attracted them. They were most excited about the workplace, though some described being worried about integrating into the UK's social and educational culture. None of the participants mentioned the legal documentation needed to certify their right to work and live in the UK as a source of stress.

\section{The early period of arrival}

When arriving in the UK and their new institutions, participants reported surprise - both positively and negatively, in contrast to early stage-frameworks that characterise the arrival phase as one full of excitement. Some were intrigued by the diversity of their workplace, with Anastasia being enchanted by the workplace culture, finding a supportive working environment and good team morale. Audra mentioned that her department assigned her a non-teaching workload during her first few months, and a mentor to help her adjust, using the metaphor 'baby-sitter' to describe how she heavily relied on her mentor to anticipate diff erences and help her feel comfortable with the new environment. For other participants, their assigned mentor was simply a name with no solid help provided.

The early days were shaped by logistical challenges of relocation, such as finding a house, which proved particularly arduous. These challenges became stressful and undermined their ability to work, as most were handed full workloads from day one. The continuous turmoil of cultural and professional challenges caused many to reflect on their prior expectations. These expectations were 
often originally unstated and implicit, although during the interviews, many explicitly shared what they hoped to find. Rudolf recalled his 'shocking' start:

Chaos! Horrible experience! Therewas no sign of being welcomed. InAustria, they would have taken care ofyou in the first few days. Here, it was shocking to hear "this is how things work". There was no support mechanism. I opened the door of this office and it was disgusting, boxes everywhere, a mess ... The whole thing was a nightmare.

Social and cultural matters affected non-academic areas of their adjustment, as some participants soon started to identify cultural differences (e.g. accent, social relationships and rules). Unfamiliarity with workplace and social routines contributed to their feelings of alienation. Qi explained this, making comparisons between initial perceptions of the UK and reality:

English people love after-work drinks. Well, I don't drink but had to socialise. If I didn't I would be left behind ... I soon realised the UK wasn't as posh as I thought. When people drink, their intellectual ability goes away. I felt like an alien seeing women in the streets dressed like naked with no self-respect getting drunk.

Personal transitional issues dominated many of the participants' professional lives for months after they commenced work, whilst certain cultural nuances made them 'furious', as David revealed:

I had house issues, accent issues, transportation issues and then offi ce routine issues, like indefinite and constant meetings. People here love meetings. For me it's a waste of time ... It's ridiculous how they spent most of their time chit chatting. This is not efficiency and I am very efficient person. Made me furious!

Teaching was morechallenging toadjust to than research. All participants mentioned thatavailability of internal and external funding and research opportunities brought moments of excitement, as they recognised the benefits of being in UK HE. However, teacher-student relationships were confusing for many. The highly regarded status of a lecturer in Asian universities differs from the UKHE, where the relationship with students is relatively non-hierarchical and informal. Qi was surprised when his students called him by his first name and emailed him informally. Lack of knowledge of UK HE terminology was overwhelming, which affected their ability to support students. Roberto said:

...things like exceptional factors, year tutor, personal tutor, degree classifications, data protection rules. These things tripped me up for months and I was like. "I don't know what you're talking about."

As Roberto said, the duties of a 'year tutor' required them to signpost students on different academic and social matters and the 'personal tutor' to help students with personal issues. Yet, dealing with students' personal issues required some understanding of young people's extra-academic lifestyles, culture and relationships that these immigrant academics did not have.

\section{Recent and current experience}

Surprise, both positive and negative, as well as optimism and frustration kept re-emerging monthseven years - after arrival to the UK when unfamiliarity with social and academic procedures were becoming more noticeable. Bouts of frustration and of longing to return home, where things are familiar and comfortable, occurred. Even when they felt they had started to adjust and do things 'right', Anastasia described her acculturation as 'a real rollercoaster where one day you feel that you can take [on] the world, and the next day you feel so frustrated thinking, "I am out of here, where do I book a flight?"'.

Andrea also voiced thoughts of escape, though did not choose to leave:

The $\mathrm{NSS}^{1}$ is a big thing here. There is a whole strategy on how to get the overall scores. I really struggled with the obsession on student satisfaction ... It was also the year when the new fees were introduced ... I felt they (students) didn't treat me respectfully and were constantly complaining ... I thought "I'm off, this isn't for me". I started applying again to go back. I had an interview six months after I came here.

A key challenge, particularly for the non-native English speakers, was stereotyping from colleagues. Hostilityalso appeared outside the university environment. However, as Sven said, 'I know that such 
incidents are unlikely within the university and that there was active anti-racism action at a university level. That is a relief'. Yet, in Fabio's institution, an in-university incident prompted his frustration. When he attended his department's Open Day, he confessed to a colleague that he was not feeling confident in talking about the programme and the city:

I told my colleague howstressed I was and he said, “Justsmilea lot. That's why you're here. And if you don'tknow the answer to something, just talk to them about spaghetti and pizza. Isn't what you Italians always talk about?" I was fuming.

The frustration elicited in some situations often took a long time to resolve because of the participants' reluctance to ask for help. Yet, this frustration was a form of self-assertion and of growing self-esteem that later helped many participants, like Fabio, to remain 'strong' and determined to survive new challenges, as will be discussed later.

Euphoric events were recounted when expectations were met or exceeded, particularly in relation to support for the academic career development that initially motivated their move. For example, Marie was 'thrilled' by the prospect of a promotion:

I remember when my colleagues encouraged me to go for a promotion to cover educational matters in strategic leadership level. Theysaw I had many ideas to improve our programmes and recommended I should think about it. I was thrilled that despite a rough start, I didn't give up and I could actually do well.

Academic promotions further empowered certain participants to establish their position. The academics were strongly motivated to boost their career in the UK and were making every effort to succeed, giving them a renewed sense of euphoria years after arriving.

\section{Future perceptions}

Participants talked about their future optimistically, with pride re-emerging, marked by their realisation of what they had achieved despite challenges. Mollie explained how her 'Americanness became synonymous with my professionalism', as she is now engaged in long-term and prestigious research projects. Despite experiencing moments of frustration, due to practices being very diff erent, her initial pride had not lessened.

Without exception, none of the study's participants would choose to return to their home country or previous institution. Even Andrea, who considered leaving the UKand had a job interview months after his arrival, chose not to leave as his UK situation gradually appeared preferable. Konstantina was typical:

I wouldn't go back ... I see the university's name next to mine and I'm proud. I've struggled and still am, but here I have progression opportunities, I can travel, I'm encouraged to bid for funding, I'm given the space to develop. I hosted one of the biggest conferences due to my networking, I'm bringing guest speakers from around the world and my students appreciate it. I'm still facing criticism from colleagues, which frustrates me ... but when I'm achieving things I know I'm in the right place.

In parallel with occasions when workplace interactions prompted frustration (e.g. racism, stereotyping) or stress (e.g. university terminology, large-class teaching), participants were also creating meaningful relationships, as they communicated more and perceived and dealt with differences more independently. As David concluded, 'I'm proud to be able to survive in two cultures', highlighting that creating relationships with colleagues and students was something he valued. Participants thought they made positive contributions and gave examples of raising their own professional profile and of contributing to their institution's success by bringing new ideas, engaging in knowledge-exchange activities and research partnerships and benefiting their students.

\section{Emotion regulation strategies}

Participants' successful acculturation was characterised by engaging in various emotion regulation strategies. Antecedent-focused emotion regulation was demonstrated by the participants' choice to 
relocate, an example of situation selection. In choosing to move to the UK, they took initiative to remove themselves from situations that were blocking their career progression. Although some considered leaving the UK when encountering obstacles, they chose to persist (situation selection). Their self-determination to survive and succeed in a foreign workplace helped these academics to thrive personally, as well as introduce new practices. Acommonly used strategy of situation selection was seeking interactions with fellow expatriates. Encounters with fellow expatriates had beneficial consequences by allowing them to see how they had adapted to UK culture and see certain events from a more benign perspective.

Participants also exercised agency by taking action to modify situations and rise to challenges (situation modification). When a student's informal email 'shocked' him, Qi tried to modify the situation by 'educating' him:

I gotan email saying "Hey Qi-howareyou? Sorry, I'll be late for class today". It was shocking how informally they wrote. But, I gathered all my politeness, humour and responded in all formality, as I wanted to teach him to write formally. I said "Dear Sam, I'm glad I forgot my coff ee in the office that made me return and see your email" accompanied with an overlong text about what he would miss.

Likewise, in attempts to alter other people's perceptions, Sven intentionally kept asking his hostile colleague's advice on research papers to prove his capability. Others, to change the emotional cost of their adaptation, attempted to make their office more familiar, by taking traditional food to work to share with colleagues, decorating their office with country and family photos, and organising house-warming parties to create a less-antagonistic image of themselves.

Participants also focused on specific elements of situations (focusing attention), such as staying at work until late for focus on work rather than 'a house full of boxes'. Other examples of redirecting their thoughts to more pleasant elements included focusing on research-oriented tasks that they found rewarding, rather than worrying about difficulties in teaching, or planning short vacations to unwind from stressful situations.

Their determination to succeed in their new environments fuelled them to reappraise situations rather than flee them. Frequently, they found humour in stressful situations and even used their foreignness to define themselves, to recreate, and to establish new perceptions. Andrea, who described his struggle to cope with the NSS pressure, reappraised his thinking to become more influential in his professional life:

\footnotetext{
When you're an immigrant, you have an escape route. You can just disappear and go home. If I were British, where would I go? Once I realised this, ithelped me move forward in an optimistic way... So rather than moan about the NSS, I decided to try some Italian-ism and do a shout-outcampaign. Italians are loud people, right? I organised a pizza party where final yearstudents got together, enjoyed pizza, listened to music, while completing the NSS! It worked!
}

In terms of response-focused regulation strategies, suppression was used to hide or fake their reactions in negatively-appraised situations. When Fabio was faced with discriminatory comments, he hid his frustration, as he did not want to look 'like a cowardly person'. For months, Konstantina 'pretended that everything was fine' masking how stressed she really felt. Likewise, Audra suppressed her frustration during the first weeks in her new institution because she was worried about 'social disapproval' from colleagues. One of her frustrations was the perception that administrative staff intruded in her work. As she was faced with the dilemma to 'fight or live with it', she chose to hide her frustration. However, while initially employing suppression, she later demonstrated reappraisal, which had different consequences for how she thought and felt:

I didn'tspeak at first and suff ered silently... Gradually, I realised that here the administrative staff takes some of ourworkload. In the US, we are administrators and academics, so we have to doall the paperwork ourselves and have total discretion ... I realised they are lovely, helpful and informative.

Some participants chose to regulate their emotions by enhancing their competencies. This type of competence-oriented regulation was mentioned by Yu-Wang, who referred to strong institutional 
support via a series of training sessions, helping him boost his confidence in teaching. Although holding a research post in his institution, he described enjoying the teaching aspect of the role, after feeling competent to meet the demands of 'heavy teaching':

In my first year of teaching, I was struggling. It tookmea long time to prepare for a class, sometimes longer than a day, even in weekends. Training courses, such as the STDU, Staff Training Development Unit were exclusive for new and international staff. These courses massively helped me. A few months later, I felt more confident.

Yu-Wang's training made it possible to experience enjoyment that comes with teaching, which was problematic at the start. Marie described investing her time in a coaching session to help her improve her management skills and develop her full potential, which would support her promotion application. Similarly, Anastasia enrolled in a basketball team made up of non-UK academics to help her personal development in social competencies. Participants clearly made choices to develop their competencies, which led to more positive feelings.

\section{Discussion}

The findings support critiques of the early descriptions of adjustment as aU-curve or fixed emotional reactions over time (e.g. Lysgaard 1955; Oberg 1960), suggesting that those models are indeed overgeneralised (Church 1982). Participants experienced acculturation as more like a roller coaster of emotions occurring (and re-occurring) throughout various periods, dependent upon their chosen emotion regulation processes. The study, therefore, is consistent with arguments that the experience of expatriates is not a passive state during which individuals simply take in what is happening to them and suff er anxiety (Zhou et al. 2008), but actively work to adjust to their new environments. Instead of a fixed, stage-like conceptualisation of acculturation, this study considered the particular experiences encountered over time (e.g. dealing with cultural nuances, new academic standards, creating relationships, achieving career progression) and the relationship between opportunities in the host culture and the immigrants' emotional regulation processes. This approach emphasises the ways in which particular emotions (e.g. frustration, euphoria, surprise, pride) were experienced iteratively across the periods of transition and the agency that the migrants exercise from initial contact to eventual long-term adjustment.

Our findings also confirm that acculturation is a two-way process by considering the impact immigrant academics have on the host culture (Jiang et al. 2010). Participants' felt like valued members who can make a significant change in their departments, supporting claims that immigrantacademics are assets for universities (Foote et al. 2008; Sanderson 2011; Svetlik and Lalić 2016). These findings are different from other studies, in which immigrant academics thought their value had not been recognised (Green and Myatt 2011) or that their influence upon the host group was limited (Jiang et al. 2010). Some of those studies (e.g. Green and Myatt 2011) had very small sample sizes. Other studies (e.g. Barkhuizen 2002) conflate early-career academics with international academics. The fact that our participants were experienced academics upon arrival may have contributed to their success. Yet, in some cases, incidents of stereotyping occurred, confirming arguments (e.g. Mizzi 2013; Tange 2010; Trowler 1998) that xenophobic behaviour is still present.

In alignment with studies on immigrant academics (e.g. Alberts 2008; Luxon and Peelo 2009; Pherali 2012), our participants' challenges involved simultaneously negotiating the unfamiliar social norms of the UK (e.g. northern accent, drinking habits) with new office practices (e.g. number of students, heavy teaching, administrative duties). However, this study illustrated how participants actively managed their emotions through various psychological processes that helped them to become authentically involved in their workplace, supporting findings that link successful emotion regulation with improved academic and work performance (Gross and John 2003).

To illustrate these mechanisms, an integrative framework of emotion regulation in academic acculturation is proposed (Figure 1), which builds on Gross's model of emotion regulation and its phases $(1998,2014,2015)$. Our findings go beyond Gross's $(1998,2014)$ five emotion regulation 


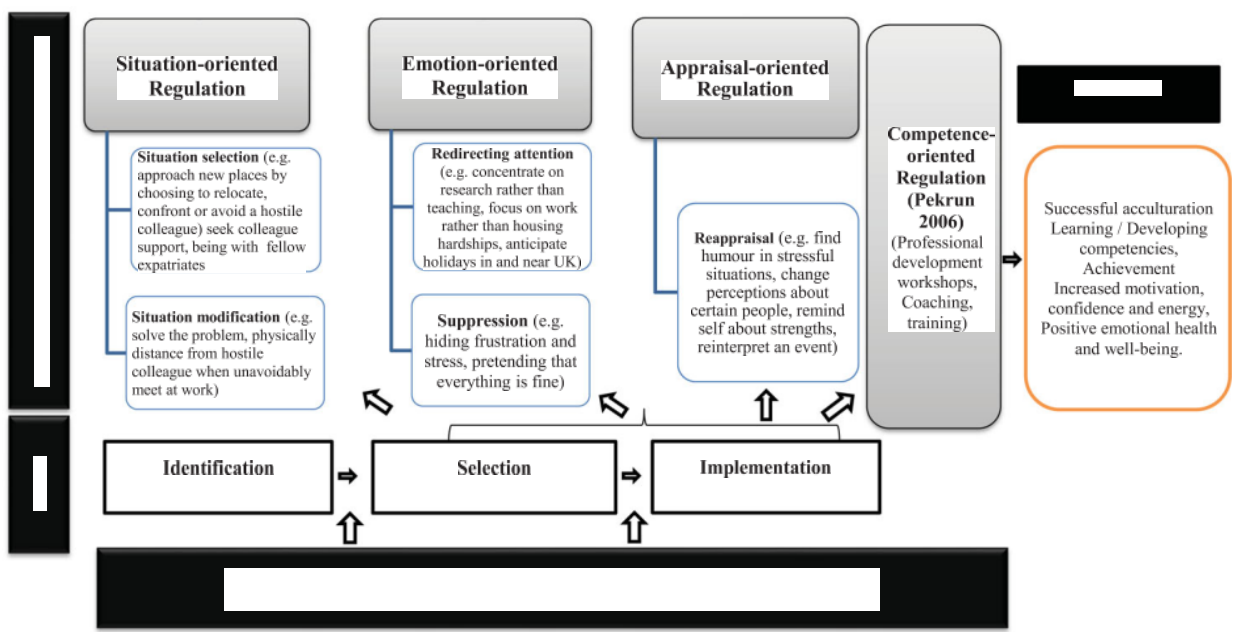

Figure 1. Emotion regulation strategies during acculturation.

strategies to include competence-oriented regulation (Pekrun 2006; Pekrun and Perry 2014), a form of regulation that involves action to develop skills and abilities to learn, improve and succeed in their new environments. Competence-training was supported by institutional initiatives that participants used to increase perceived control, self-confidence and achievement and changed their emotions, facilitating their successful adjustment.

Antecedent-focused strategies, such as situation selection (e.g. seek fellow expatriates), situation modification (e.g. solve problem), and redirecting attention (e.g. focus on research) were mentioned as eff ective and used in parallel, which accords with research (e.g. Diefendorff, Richard, and Yang 2008; Gross and Thompson 2007) that the use of multiple emotion regulation strategies may be more efficient. Consistent with previous research on academics' acculturation (e.g. Green and Myatt 2011; Moody 2004), being amongst people that made them feel good, especially fellow expatriates, was a powerful regulation strategy (situation selection), as it

helped the participants realise how far they had come. Reappraisal was the most commonly reported strategy and led to long-term benefits by enabling to recover from setbacks (Gross and John 2003; John and Gross 2004). The model also considers the underlying psychological factors that underpin the identification, selection and implementation of emotion regulation strategies. Participants' choice to engage in emotional regulation seemed to be rooted in their persistence and conviction that they were in the UK to succeed. This tendency to actively fight the challenges strengthens arguments that immi- grant academics are highly self-sufficient, independent, and better adjusted to cross-cultural tran- sition because it has been their choice to relocate (situation selection in the first place) (e.g. Peltokorpi and Froese 2009). Their self-efficacy and self-drive seemed to underlie their eff orts to change their thoughts and behaviours to survive the challenges (Tamir 2016). On the other hand, sup- pression, a variant of emotion-oriented regulation (Pekrun and Perry 2014) was used in stressful or frus- trating situations, particularly where they were concerned about image-management. Feigning contentment rather than expressing stress when facing practical difficulties and lack of sympathy from senior management was associated with poor mental well-being (Diefendorff, Richard, and Yang 2008; Gross 1998) and to temporary thoughts of leaving the UK.

It is possible that because these interviewees had an established career trajectory before moving to the UK they were more capable of exercising agency and being persistentand disciplined, making acculturation a smoother process (Jiang etal. 2010). Therefore, by choosing to interview those who had survived at least a year and a half (the average length of residence in the UK among the sample was 7 years) the study highlighted the strategies of those who were successful. It is also possible that 
these academics' strong motives to succeed, their emotion-regulation self-efficacy, and emotion regulation aptitudes have influenced the phases of emotion regulation (e.g. identification) at all stages of emotion regulation (e.g. situation selection), as discussed by Gross (2015).

\section{Implications}

This study has important practical implications. The experience of some participants suggested examples of good practices in supporting immigrant academics, namely addressing work-life balance challenges associated with transition, providing competence-training and an active mentor, and a term without teaching to acclimate. Emotion regulation interventions designed by institutions to teach healthier patterns of emotion regulation could be offered, which have been suggested as eff ective for minorities working in academic contexts (Gross 2014). Further recommen- dations for universities to foster acculturation may include: a mandatory induction programme that embeds aspects of the UK HE system and social and cultural aspects of life in the UK; an organised plan for preparing academics for their transfer to the UK (e.g. paid pre-visit, prearranged/pre-paid temporary accommodation, explicit provision of counselling facilities on arrival); the establishment of support groups for immigrant academics and their families; and 'accent adjustment programs' that aim to help non-native English speakers communicate more effectively by reducing their foreign accent and helping them understand local accents.

Eff ective mentoring can ease immigrant academics' acculturation, but like similar studies (Collins 2008; Trowler 1998), this study found that mentors were often absent. Essential steps could involve the assignment of a mentoring committee to each immigrant academic, comprising of several enthusiastic mentors, who have formally gained cross-cultural competency training, and who are both from and outside the mentee's department (Moody 2004). To ensure mentors' commitment, institutions could provide incentives such as compensation or release from teaching responsibilities (Harnish and Wild 1994).

\section{Limitations}

While phenomenology is not designed to assure statistical generalisability, its strength lies in the potential to gain rich and dense data about unexplored phenomena and to refine understanding of existing theories (Gill2014). In this case, the study critiques stage theories of acculturation, advancing the use of Gross's theory in the context of academic acculturation. Consistent with phenomenological guidelines (e.g. Crist and Tanner 2003; Sandberg 2000), we emphasised the richness of the qualitative accounts over quantity of data, and on the illumination of the participants' 'worlds'. The findings were developed from the narratives of a diverse group of participants, ranging in age, discipline, countries of origin, and experiences of work and life, that allowed us to gain the essence of immigrant academics' acculturation in the context as they experienced it. Thus, the identified themes are shared by a diverse sampleand may be recognisable toand, thus, transferable to otherimmigrant academics beyond this study (Lincoln and Guba 1985). Without precluding the possibility that there are other ways in which acculturation is experienced, the systematic analysis of collective themes across a diverse sample until saturation was reached contributes to the trustworthiness of the data and that the findings will be broadly recognised by other immigrant academics.

Further research, in a diff erent paradigm, would be needed to understand systematically how particular personality traits or motivational variables (Tamir 2016) affected the choice of emotion regu- lation strategies (Diefendorff, Richard, and Yang 2008). Our participants appeared resilient, highly motivated and determined to recover and grow from challenging experiences, in line with person- ality traits found in studies on immigrant academics (e.g. Foote et al. 2008; Zhou et al. 2008). As it was a self-selected sample, those who were suffering from mental health issues would likely not have participated. Nonetheless, an interview like this could be used by potential participants as a 
form of connection and social support, so those who were still actively struggling might have welcomed an opportunity to talk about it in a safe space.

The study only included immigrant academics from three universities in north-western England. Although experiences were broadly similar across all three universities (which represented diff erent institutional types), immigrant academics' experiences may be different in other parts of the UK or in other countries, as policies and practices may differ. Future studies might investigate other institutions in different parts of the UK and consider immigrant academics' contributions to their university from the perspectives of their colleagues, managers and students.

Despite these limitations, this study offers a new lens for understanding the experiences of immi- grant academics, framing them as resilient individuals who - throughout the period of adaptation - actively managed their emotions in the face of challenges in ways that ultimately supported their success. Describing and understanding the cultural and academic adjustment process may help immigrant academics to realise how to manage the emotional rollercoaster of acculturation. It may also help institutions to anticipate the challenges these academics face and put in place appro- priate support systems.

\section{Note}

1. National Survey of Students, a satisfaction surveyed administered to all final year undergraduates in UK universities that serves as a key quality indicator.

\section{Disclosure statement}

No potential conflict of interest was reported by the authors.

\section{Funding}

This work was supported by Society for Research into Higher Education: [Grant Number Newer Researchers prize 2015 / $£ 3000]$.

\section{ORCID}

Kathleen M. Quinlan (1) http://orcid.org/0000-0003-3606-4148

\section{References}

Adler,P. S. 1975. "The Transitional Experience: An Alternative View of Culture Shock." JournalofHumanistic Psychology 15 (4): 13-23.

Alberts, H. C. 2008. "The Challenges and Opportunities of Foreign-Born Instructors in the Classroom." Journal of Geography in Higher Education 32 (2): 189-203.

Barkhuizen, G. 2002. "Beginning to Lecture at University: A Complex Web of Socialization Patterns." Higher Education Research \& Development 21 (1): 93-109.

Benner, P. 1994. Interpretive Phenomenology: Embodiment, Caring, and Ethics in Health and IIIness. Thousand Oaks, CA: Sage.

Berry, J.W. 1997. "Immigration, Acculturation, and Adaptation." Applied Psychology46(1): 5-34.

CEC. 2007. Green Paper: The European Research Area: New perspectives, COM (2007) 161, Brussels.

Church, A. T. 1982. "Sojourner Adjustment." Psychological Bulletin 91 (3): 540-572.

Collins, J. 2008. "Coming to America: Challenges for Faculty Coming to United States' Universities." Journal of Geography in Higher Education 32 (2): 179-188.

Crist, J. D., and C. A. Tanner. 2003. "Interpretation/Analysis Methods in Hermeneutic Interpretive Phenomenology." Nursing Research 52 (3): 202-205.

Diefendorff, J. M., E. M. Richard, and J. Yang. 2008. "Linking Emotion Regulation Strategies to Affective Events and Negative Emotions at Work." Journal of Vocational Behavior 73 (3): 498-508.

European Commission/EACEA/Eurydice. 2015. The European Higher Education Area in 2015: Bologna Process Implementation Report. Luxembourg: Publications Office of the European Union. 
Foote, K. E., W. Li, J. Monk, and R. Theobold. 2008. "Foreign-Born Scholars in US Universities: Issues, Concerns and Strategies." Journal of Geography in Higher Education 32 (2):167-178.

Gill, M.J.2014. "ThePossibilities of Phenomenology for Organizational Research." Organizational ResearchMethods 17 (2): 118-137.

Goulding, C. 2005. "Grounded Theory, Ethnography and Phenomenology: A Comparative Analysis of Three Qualitative Strategies for Marketing Research." European Journal of Marketing 39 (3/4): 294-308.

Green, W., and P. Myatt. 2011. "Telling Tales: A Narrative Research Study of the Experiences of New International Academic Staff at an Australian University." International Journal for Academic Development 16 (1): 33-44.

Gross, J. J. 1998. "Antecedent-and Response-Focused Emotion Regulation: Divergent Consequences for Experience, Expression, and Physiology." Journal of Personality and Social Psychology 74 (1): 224-237.

Gross, J. J. 2014. "Emotion Regulation: Conceptual and Empirical Foundations." In Handbook of Emotion Regulation, 2nd ed., edited by J. J. Gross, 3-20. New York: Guilford.

Gross, J. J. 2015. "Emotion Regulation: Current Status and Future Prospects." Psychological Inquiry 26 (1): 1-26.

Gross, J. J., and O. P. John. 2003. "Individual Diff erences in Two Emotion Regulation Processes: Implications for Aff ect, Relationships, and Well-Being." Journal of Personality and Social Psychology 85 (2): 348-362.

Gross, J. J. and R. A. Thompson. 2007. "Emotion Regulation: Conceptual Foundations." In Handbook ofEmotion Regulation, edited by J. J. Gross, 3-24. New York: Guilford press.

Harnish, D., and L. A. Wild. 1994. "Mentoring Strategies for Faculty Development." Studies in Higher Education 19 (2): 191-201.

HESA (Higher Education Statistics Agency). 2017. Staff in HigherEducation 2015/16. https://www.hesa.ac.uk/stats-staff .

Hopson, B., and J. Adams. 1976. "Towards an Understanding of Transition: Defining Some Boundaries of Transition Dynamics." In Transition: Understanding \& Managing Personal Change, edited by J. D. Adams, J. Hayes, and B. Hopson, 3-25. London: Martin Robertson.

Hsieh, H. H. 2012. "Challenges Facing Chinese Academic Staff in a UKUniversity in Terms of Language, Relationships and Culture." Teaching in Higher Education 17 (4): 371-383.

Jiang, X., R. Di Napoli, M. Borg, R. Maunder, H. Fry, and E. Walsh. 2010. "Becoming and Being an Academic: The Perspectives of Chinese Staff in Two Research-Intensive UK Universities." Studies in Higher Education 35 (2): 155-170.

John, O. P., and J. J. Gross. 2004. "Healthy and Unhealthy Emotion Regulation: Personality Processes, Individual Diff erences, and Life Span Development." Journal of Personality 72 (6): 1301-1334.

Kim, T., and W. Locke. 2010. Transnational Academic Mobility and the Academic Profession. In Higher Education in Society: A Research Report. http://www.open.ac.uk/cheri/documents/HigherEducationandSociety.pdf.

Lincoln, Y. S., and E. G. Guba. 1985. Naturalistic Inquiry. Newbury Park, CA: SAGE.

Lund, D., R. Hibbins, and M. Barker. 2007. "Organisational Eff ectiveness of Immigrant Staff in Australia: Sustaining a Culturally Diverse Workforce." International Journal of Environmental, Cultural, Economic \& Social Sustainability 3 (3): 79-88.

Luxon, T., and M. Peelo. 2009. "Academic Sojourners, Teaching and Internationalisation: The Experience of Non-UKStaff in a British University." Teaching in Higher Education 14:649-659.

Lysgaard, S. 1955. "Adjustment in a Foreign Society: Norwegian Fulbright Grantees Visiting the United States." International Social Science Bulletin 7: 45-51.

Mizzi, R. 2013. "Crossing Borders to Teach: A Literature Review of (Dis)location, Interconnectedness, and Pedagogy." The Canadian Journal for the Study of Adult Education 25 (2): 53-63.

Moody, J. 2004. Faculty Diversity: Problems and Solutions. New York: Routledge.

Oberg, K. 1960. "Culture Shock: Adjustment to New Cultural Environments." Practical Anthropology 7: 177-182.

Pekrun, R. 2006. "The Control-Value Theory of Achievement Emotions: Assumptions, Corollaries, and Implications for Educational Research and Practice." Educational Psychology Review 18 (4): 315-341.

Pekrun, R., and R. Perry. 2014. "Control-Value Theory of Achievement Emotions." In International Handbook of Emotion, in Education, edited by R. Pekrun, and L. Linnenbrink-Garcia, 120-141. New York: Routledge.

Peltokorpi, V., and F.J. Froese. 2009. "Organisational Expatriates and Self-Initiated Expatriates: Who Adjusts Better to Work and Life in Japan?" International Journal of Human Research Management 20 (5): 1095-1111.

Pherali, T. J. 2012. "Academic Mobility, Language, and Cultural Capital: The Experience of Transnational Academics in British Higher Education Institutions." Journal of Studies in International Education 16 (4): 313-333.

Quinlan, K. Q.2016."Seven StancesonEmotioninEducation."InHowHigherEducationFeels:CommentariesonPoemsthat Illuminate Emotions in Learning and Teaching, edited by K. M. Quinlan, 9-21. Rotterdam, NE: Sense Publishers.

Richardson, J., and S. McKenna. 2003. "International Experience and Academic Careers: What Do Academics Have to Say?" Personnel Review 32 (6): 774-795.

Richardson, J., and J.Zikic. 2007. "The Darker Side of an International Academic Career." CareerDevelopment International 12 (2): 164-186.

Sandberg, J. 2000. "Understanding Human Competence at Work: An Interpretative Approach." Academy of Management Journal 43 (1): 9-25. 
Sanderson, G. 2011. "Internationalisationand Teaching in HigherEducation." HigherEducationResearchand Development 30 (5): 661-676.

Svetlik, I., and A. Lalić. 2016. "The Impact of the Internationalisation of Higher Education on Academic Staff Development - The Case of Slovenian Public Universities." Studies in Higher Education 41 (2): 364-380.

Tamir, M. 2016. "Why Do People Regulate their Emotions? A Taxonomy of Motives in Emotion Regulation." Personality and Social Psychology Review 20 (3): 199-222.

Tange, H. 2010. "Caught in the Tower of Babel: University Lecturers' Experiences with Internationalisation." Language and Intercultural Communication 10 (2): 137-149.

Trowler, P. 1998. Academics Responding to Change: New Higher Education Frameworks and Academic Cultures. Buckingham, UK: Society for Research into Higher Education \& Open University Press.

UCEA (University \& Colleges Employers Association). 2008. Recruitmentand Retention of Staff in Higher Education. http:// www.universitiesuk.ac.uk/highereducation/Pages/RecruitmentRetention.aspx.

Universities UK. 2015. Patterns and Trends in UK Higher Education 2015. www.universitiesuk.ac.uk/highereducation/ Pages/PatternsAndTrends2015.aspx.

Zhou, Y., D. Jindal-Snape, K. Topping, and J. Todman. 2008. "Theoretical Models of Culture Shock and Adaptation in International Students in Higher Education." Studies in Higher Education 33 (1): 63-75. 